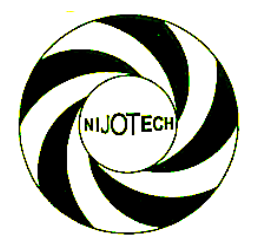

Nigerian Journal of Technology (NIJOTECH)

Vol. 39, No. 4, October 2020, pp. 1276 - 1285

Copyright@ Faculty of Engineering, University of Nigeria, Nsukka

Print ISSN: 0331-8443, Electronic ISSN: 2467-8821

www.nijotech.com

http://dx.doi.org/10.4314/nit.v39i4.37

\title{
OPTIMIZATION TECHNIQUE IN RAINFALL - INTENSITY - DURATION - FREQUENCY MODELLING FOR IKEJA, SOUTH-WEST, NIGERIA
}

\author{
A. O. David ${ }^{1}$ and I. L. Nwaogazie ${ }^{2, *}$ \\ 1, Dept of Civil Engineering, Olabisi Onabanjo University, Ibogun Campus, Ogun State, Nigeria. \\ 2, DePT OF Civil \& ENVIRONMENTAL ENGR'G, UNIVERSITY OF PORT HARCOURT, RIVERS STATE, NIGERIA. \\ Email addresses: ${ }^{1}$ adekunle.david@oouagoiwoye.edu.ng, ${ }^{2}$ ifynwaogazie@yahoo.com
}

\begin{abstract}
The adequate estimation of rainfall intensity over a particular catchment is a necessary procedure in the design of water resources engineering control structures. To develop the probability and non - probability distribution function models for rainfall intensity - duration frequency for Ikeja, 25 year daily rainfall data were collected from Nigerian Meteorological Agency (NIMET) Abuja for Ikeja. The annual maximum rainfall amounts with durations of 5, 10, $15,20,30,45,60,90,120,180,240,300$ and 420 minutes were extracted and subjected to frequency analysis using the Excel Optimization Solver wizard. To develop the rainfall intensity, duration and frequency (IDF) models, specific and general IDF models were obtained for return periods of 2, 5, 10, 25, 50 and 100 years using the Gumbel Extreme Value Type - 1, Normal and Log Pearson Type - 3 distributions. The Anderson Darling goodness of fit test was used to ascertain the best fit probability distribution. The $R^{2}$ values ranged from $0.992-0.993$ and the Mean Squared Error, MSE from 26.43 - 115.94 for the Gumbel; $0.992-0.993$ with MSE of 28.64 - 85.23 for Normal distribution and 0.991 - 0.993 with MSE of 28.24 - 154.85 for Log Pearson Type - 3.The prediction of rainfall intensity with the Probability Distribution Functions showed a good match with observed intensity values. The intensity - duration curve in all cases has a negative slope. The GEVT - 1 and Normal distribution models ranked first while Log-Pearson Type 3 ranked third with respect to $R^{2}$ and MSE in the non-specified return period. The probability distribution models are recommended for the prediction of rainfall intensities for Ikeja metropolis.
\end{abstract}

Keywords: IDF models, Gumbel Extreme Value Type - 1, Normal, Log Pearson Type - 3 distributions, Excel Optimization Solver, goodness of fit test, Ikeja.

\section{INTRODUCTION}

The Rainfall Intensity Duration Frequency (IDF) relationship is one of the most commonly used tools for the design of hydraulic and water resources engineering control structures. Mathematical knowledge could be employed in the development of a relationship between the rainfall intensity, duration and the frequency (return period). The establishment of such relationship was done as early as 1932 [1]. The knowledge of the frequency of extreme events such as floods, droughts, rainstorm and high winds is required in the adequate planning and design for these extreme events [2]. The planning and designing of various water resources projects require the use of IDF relationship [3]. This relationship is determined through frequency analysis of data from meteorological stations. The IDF formulae are the empirical equations representing a relationship among maximum rainfall intensity (as dependent variable) and other parameters of interest, such as rainfall duration and frequency (as independent variables). There are

* Corresponding author, tel: +234 - 803-339-9923 
several commonly used functions found in the literature of hydrology applications [1]. Owing to its wide applications, accurate estimation of intensityduration-frequency relationship has received attention from researchers and scientists from all over the world [4]. All functions have been widely applied in hydrology. In Nigeria, a lot of work has been done in South - East and South - South. For instance, the IDF models of [5] in Port Harcourt and that of [6] at Eket in Akwa Ibom State. All these models generated IDF curves that confirm the theory for shorter recurrence periods of 2 to 10 years.

\section{MATERIALS AND METHODS}

\subsection{Study Area}

Ikeja is the capital of Lagos State in South - West Nigeria. It covers an estimated area of about 40.60 $\mathrm{km}^{2}$. It is located at $41 \mathrm{~m}$ above the sea level and falls within latitude $6.59^{\circ} \mathrm{N}$ and longitudes $3.34^{\circ} \mathrm{E}$ (see Figure 1). Ikeja lies in the plane which is developed on rocks of the basement complex found in the Savannah zone. The area is characterized by relatively high temperature with mean annual temperature of $30^{\circ} \mathrm{C}$ and rainfall of $1,314.4 \mathrm{~mm}$ [7].

\subsection{Data Collection}

The major material used for this work is rainfall data comprising of the amount and duration. A twenty five (25) year rainfall data which included data ranging from 1986 to 2010 were obtained from Nigeria Meteorological Agency (NIMET) office Abuja, Nigeria. The data were sorted and arranged according to years, rainfall intensities and durations. The rainfall intensities selected for the analysis were the maximum values for each year for all the years analysed.

\subsection{Data Analysis}

The annual maximum rainfall amount was obtained by selecting the maximum amount of rainfall for each year for $5,10,15,20,30,45,60,90,120,180,240$, 300 , and 420 durations (minutes) for the 25 year period. The IDF relation is mathematically expressed as follows:

$$
I=f(T, d)
$$

Where $\mathrm{I}=$ rainfall intensity $(\mathrm{mm} / \mathrm{hr}), \mathrm{T}=$ return period (year) and $d=$ duration (minutes).

The rainfall amount is converted to intensity $(\mathrm{mm} / \mathrm{hr})$ by dividing the amount by the duration (minutes) then multiplying by 60 as a conversion factor. For instance, given rainfall amount of $35.9 \mathrm{~mm}$ for 5 minutes duration yields an intensity of $(35.9 / 5) \times 60$ $=430.8 \mathrm{~mm} / \mathrm{hr}$. Table 1 shows all the intensities for various durations.

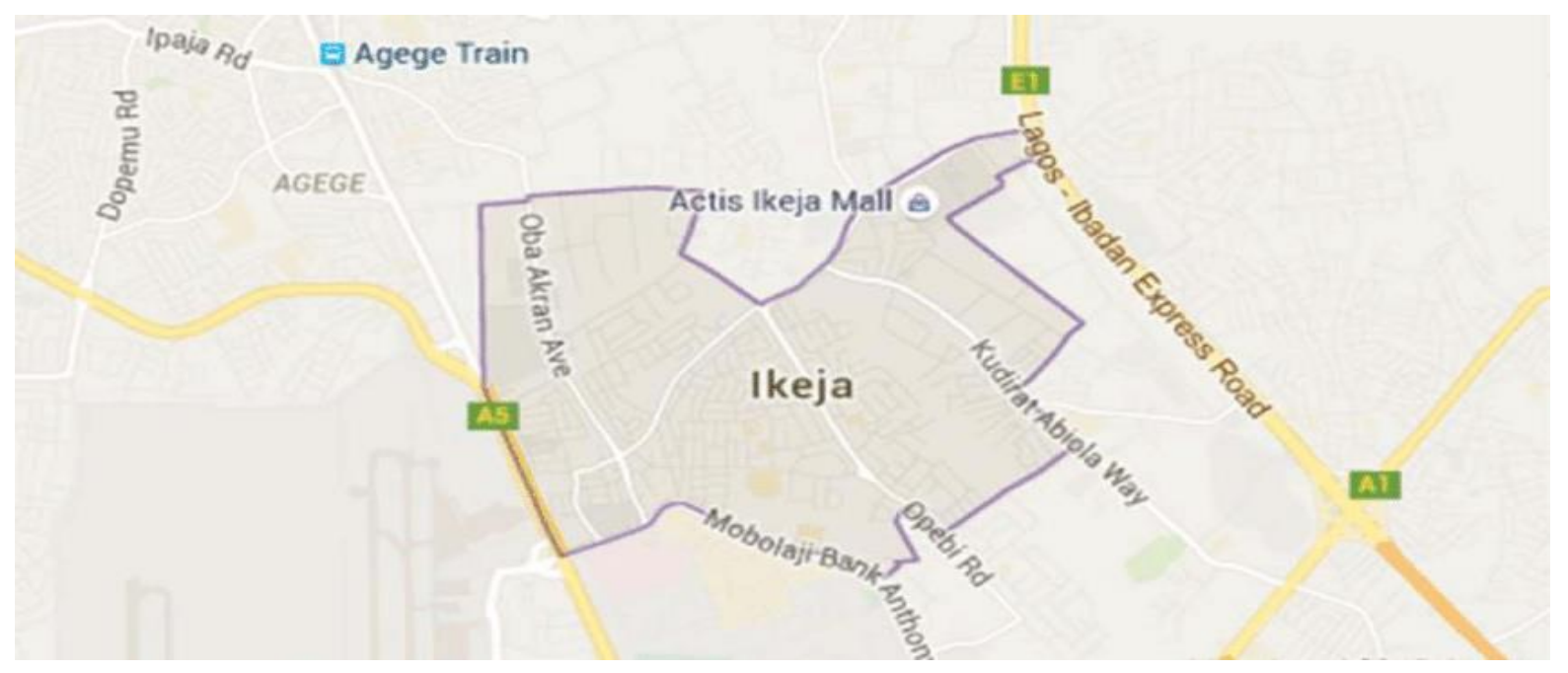

Figure 1: Location map of Ikeja in South-Western Nigeria; Source: Google map (2019)

Table 1: Ranked Observed Annual Rainfall Intensities ( $\mathrm{mm} / \mathrm{hr}$ ) for different Durations (minutes) for Ikeja

\begin{tabular}{lccccccccccccc}
\hline \multirow{2}{*}{ Year } & \multicolumn{10}{c}{ Rainfall intensity $(\mathrm{mm} / \mathrm{hr})$} \\
& 5 & 10 & 15 & 20 & 30 & 45 & 60 & 90 & 120 & 180 & 240 & 300 & 420 \\
\hline 1 & 430.8 & 280.8 & 229.2 & 188.7 & 134.2 & 99.7 & 85.2 & 65.1 & 53.7 & 39.6 & 33.5 & 29.3 & 33.9 \\
2 & 345.6 & 271.6 & 224.8 & 178.2 & 133.6 & 95.1 & 82.3 & 64.3 & 51.8 & 39.4 & 32.6 & 28.1 & 22.5 \\
\hline
\end{tabular}




\begin{tabular}{|c|c|c|c|c|c|c|c|c|c|c|c|c|c|}
\hline \multirow{2}{*}{ Year } & \multicolumn{13}{|c|}{ Rainfall intensity (mm/hr) } \\
\hline & 5 & 10 & 15 & 20 & 30 & 45 & 60 & 90 & 120 & 180 & 240 & 300 & 420 \\
\hline 3 & 305.8 & 225.0 & 207.3 & 171.9 & 130.6 & 90.8 & 71.3 & 62.8 & 48.8 & 35.8 & 29.6 & 26.8 & 21.7 \\
\hline 4 & 291.6 & 193.2 & 187.2 & 171.1 & 126.0 & 89.5 & 68.1 & 56.8 & 48.3 & 32.5 & 26.9 & 23.7 & 20.9 \\
\hline 5 & 278.4 & 192.7 & 158.0 & 140.4 & 125.8 & 89.1 & 67.1 & 53.4 & 42.6 & 32.2 & 24.4 & 21.5 & 19.1 \\
\hline 6 & 276.4 & 188.4 & 152.4 & 121.4 & 114.6 & 86.0 & 66.8 & 47.5 & 40.1 & 28.4 & 24.1 & 20.0 & 16.9 \\
\hline 7 & 267.5 & 184.2 & 150.0 & 118.5 & 100.4 & 84.0 & 64.5 & 45.4 & 38.0 & 28.1 & 23.2 & 19.5 & 15.9 \\
\hline 8 & 266.0 & 174.1 & 147.0 & 114.3 & 93.6 & 83.9 & 63.0 & 44.7 & 36.8 & 26.7 & 21.3 & 19.3 & 15.3 \\
\hline 9 & 243.1 & 172.8 & 132.9 & 112.5 & 92.6 & 70.7 & 62.9 & 44.5 & 35.7 & 25.4 & 20.9 & 18.0 & 14.4 \\
\hline 10 & 206.4 & 168.5 & 128.8 & 109.7 & 83.7 & 66.9 & 60.3 & 44.5 & 35.7 & 25.3 & 20.3 & 17.5 & 13.9 \\
\hline 11 & 202.8 & 167.6 & 128.6 & 106.1 & 81.0 & 65.6 & 58.3 & 43.0 & 33.4 & 24.5 & 20.3 & 17.4 & 13.9 \\
\hline 12 & 195.6 & 153.2 & 127.9 & 105.6 & 80.6 & 64.1 & 52.7 & 42.0 & 33.2 & 24.4 & 20.1 & 17.0 & 13.9 \\
\hline 13 & 195.2 & 151.8 & 125.6 & 96.6 & 79.0 & 63.9 & 51.0 & 40.2 & 32.3 & 23.8 & 20.0 & 16.2 & 13.8 \\
\hline 14 & 180.0 & 145.8 & 122.8 & 96.5 & 75.0 & 62.4 & 50.8 & 40.2 & 32.1 & 23.8 & 19.0 & 16.0 & 12.9 \\
\hline 15 & 177.4 & 139.2 & 116.9 & 94.2 & 73.6 & 61.8 & 50.2 & 38.9 & 32.0 & 22.3 & 18.4 & 15.9 & 12.7 \\
\hline 16 & 175.4 & 126.0 & 115.2 & 93.6 & 67.6 & 61.5 & 49.2 & 38.7 & 31.5 & 22.3 & 17.8 & 15.2 & 12.2 \\
\hline 17 & 157.0 & 124.8 & 101.2 & 92.1 & 65.2 & 56.2 & 48.1 & 35.8 & 30.2 & 22.3 & 17.8 & 15.0 & 11.6 \\
\hline 18 & 154.8 & 123.6 & 97.2 & 86.4 & 64.4 & 52.7 & 46.8 & 35.4 & 30.0 & 21.5 & 16.7 & 14.3 & 11.4 \\
\hline 19 & 147.6 & 122.9 & 93.8 & 79.2 & 62.4 & 50.0 & 46.4 & 34.1 & 29.2 & 21.0 & 16.1 & 14.3 & 10.9 \\
\hline 20 & 145.7 & 111.7 & 92.8 & 77.4 & 61.4 & 47.2 & 41.3 & 33.5 & 26.9 & 20.1 & 15.8 & 13.4 & 10.2 \\
\hline 21 & 145.6 & 111.6 & 89.6 & 72.9 & 59.1 & 45.1 & 39.5 & 30.2 & 25.6 & 20.0 & 15.1 & 12.9 & 10.2 \\
\hline 22 & 142.1 & 110.5 & 85.3 & 70.4 & 57.6 & 45.1 & 37.5 & 28.4 & 25.2 & 18.4 & 15.1 & 12.7 & 10.2 \\
\hline 23 & 138.1 & 101.4 & 84.3 & 69.6 & 53.7 & 44.7 & 37.2 & 26.3 & 23.8 & 17.9 & 15.0 & 12.6 & 9.5 \\
\hline 24 & 133.2 & 98.9 & 83.2 & 69.6 & 53.1 & 44.4 & 33.8 & 25.8 & 23.5 & 17.9 & 14.8 & 12.1 & 9.3 \\
\hline 25 & 129.6 & 97.5 & 82.4 & 62.4 & 47.5 & 41.0 & 33.8 & 25.5 & 21.6 & 16.8 & 13.8 & 12.1 & 9.2 \\
\hline Mean & 181.2 & 138.3 & 116.9 & 96.7 & 77.9 & 67.1 & 57.2 & 41.9 & 32.5 & 24.7 & 18.8 & 15.1 & 11.2 \\
\hline $\begin{array}{l}\text { Standard } \\
\text { Deviation }\end{array}$ & 59.0 & 43.2 & 35.3 & 32.8 & 28.5 & 21.2 & 15.7 & 10.2 & 8.1 & 6.6 & 4.9 & 3.9 & 2.9 \\
\hline $\begin{array}{l}\text { Coefficient } \\
\text { of } \\
\text { Skewness }\end{array}$ & 1.16 & 0.54 & 0.85 & 0.72 & 0.62 & 0.29 & 0.33 & 0.43 & 0.06 & 2.36 & 2.36 & 2.39 & 2.07 \\
\hline
\end{tabular}

The magnitudes of rainfall intensities were obtained using frequency analysis. Three probability distributions, namely Gumbel Extreme Value Type 1 (GEVT-1), Normal and Log-Pearson Type - 3 were used to obtain the magnitude of rainfall intensities for different return periods.

\subsubsection{Gumbel's Extreme Value Type - 1 Distribution}

Gumbel distribution is one commonly used probability distribution for obtaining the rainfall intensity values [5]. The rainfall intensity values were obtained using Equation (2):

$$
\mathrm{X}_{\mathrm{T}}=\bar{X}+\mathrm{K}_{\mathrm{T}} \mathrm{S}
$$

Where $X_{T}=$ rainfall intensity values (magnitude of hydrologic event); $\bar{X}=$ mean; $\mathrm{K}_{\mathrm{T}}=$ Gumbel's frequency factor; $\mathrm{S}=$ standard deviation

The Gumbel's frequency factor is obtained using Equation (3):

$$
K_{T}=\frac{\sqrt{6}}{\pi}\left\{0.5772+\operatorname{In}\left[\operatorname{In}\left(\frac{T}{T-1}\right)\right]\right\}
$$

Where $\mathrm{T}=$ return period (years)

For example, Gumbel frequency factor for a 5 year return period is evaluated as:

$$
K_{T}=\frac{\sqrt{6}}{\pi}\left\{0.5772+\operatorname{In}\left[\operatorname{In}\left(\frac{5}{5-1}\right)\right]\right\}=0.719
$$

The resulting Gumbel $K_{T}$ values for different return periods as calculated are shown in Table 2.

\subsubsection{Normal Distribution for Ikeja}

Normal distribution was applied here for frequency analysis as the probability distribution to fit the data. The rainfall intensity values are computed with Equation (2). The Normal distribution frequency factor is computed using Equation (4): $K_{T N}=w$

$=\frac{2.515517+0.802853 w+0.010328 w^{2}}{1+1.432788 w+0.189269 w^{2}+0.001308 w^{2}}$ 
where $\mathrm{w}=$ Intermediate Variable and is given in Equation(5) as:

$$
w=\left[\operatorname{In}\left(\frac{1}{P^{2}}\right)\right]^{1 / 2}
$$

and $\mathrm{P}=$ exceedance probability given in Equation (6) as:

$$
P=\frac{1}{T}
$$

where $\mathrm{T}=$ return period

Example: Normal distribution frequency factor for a 5 year return period

$\mathrm{P}=\frac{1}{5}=0.2$, and $\mathrm{w}=\left[\operatorname{In}\left(\frac{1}{0.2^{2}}\right)\right]^{1 / 2}=1.794$

Substituting computed $w$ value into Equation (4) yields:

$\begin{array}{ll}\mathrm{K}_{\mathrm{TN}} & =\mathrm{W}\end{array}$

$2.515517+0.802853(1.794)+0.010328(1.794)^{2}$

$\overline{1+1.432788(1.794)+0.189269(1.794)^{2}+0.001308(1.794)^{3}}$

$\mathrm{K}_{\mathrm{TN}}=0.841457$

Table 3 shows the calculated $\mathrm{K}_{\mathrm{TN}}$ values for different return periods.

\subsubsection{Log Pearson Type - 3 distribution}

"If $\log x$ follows a Pearson Type - 3 distribution, then $x$ is said to follow a log-Pearson Type - 3 distribution" [8]. In the United States, this distribution is the standard distribution for frequency analysis of annual maximum floods [1].

\subsubsection{Calibration of Sherman (1932) IDF model}

According to [1], Sherman's IDF model is given as;

$$
I=\frac{C T_{r}{ }^{m}}{T_{d}{ }^{a}}
$$

Where $\mathrm{c}, \mathrm{m}$ and $\mathrm{a}$ are model parameters.

Equation (7) is non-linear quotient power law that was calibrated for $\mathrm{c}, \mathrm{m}$, and a parameters using intensity, duration and return period values in Table 1 and Excel Optimization Solver. The Generalized Reduced Gradient (GRG) solver is an optimization tool embedded in Microsoft excel. It can be used to obtain the optimum values of parameters of linear or nonlinear equations. There are two solver methods namely linear programming solver (LP) for linear equations; GRG and Evolutionary solver for nonlinear Equations [4]. The premium solver [8] has details of optimization algorithms in Microsoft Excel.

\subsubsection{Goodness of fit test}

The data in Table 1 was subjected to AndersonDarling test to ascertain the probability distribution that best fit the rainfall annual maximum amount. This is a nonparametric test of the equality of continuous, one dimensional probability distributions that can be used to compare a sample with a reference probability distribution. GEVT-1, Log Pearson Type-3 and Normal distributions best fit the rainfall intensities with significant values of $0.7570,0.7538$ and 0.7115 at $5 \%$ confidence level respectively in descending order.

\section{RESULTS}

\subsection{Computation of rainfall intensities}

The rainfall intensity values were computed by evaluating Equation (1). The graphical illustration of the procedure is as shown in Figure 2. Rainfall intensity using GEVT-1 distribution with the mean and standard deviation are obtained from Table 1. For a 5 minutes duration and 2 year return period, the probability equivalent of rainfall intensity via GEVT- 1 is $\mathrm{X}_{\mathrm{T}}=\bar{X}+\mathrm{K}_{\mathrm{T}} \mathrm{S}>\mathrm{X}_{\mathrm{T}}=200.3+(-$ $0.16425 \times 147.52))>X_{T}=200.3-24.23>X_{T}=$ $176.07 \mathrm{~mm} / \mathrm{hr}$. Figure 3 shows rainfall intensity distributions and return periods using GEVT-1 distribution. Figure 4 shows rainfall intensity distributions and return periods using Normal distribution.

Table 2: Gumbel frequency factor for Ikeja IDF modelling

\begin{tabular}{lllllll}
\hline Return Period (year) & 2 & 5 & 10 & 25 & 50 & 100 \\
\hline$K_{T}$ values & -0.16425 & 0.719 & 1.304 & 2.044 & 2.592 & 3.1363 \\
\hline
\end{tabular}

Table 3: Normal distribution frequency factor

\begin{tabular}{ccccccc}
\hline Return Period & 2 & 5 & 10 & 25 & 50 & 100 \\
\hline $\mathrm{P}$ & 0.5 & 0.2 & 0.1 & 0.04 & 0.02 & 0.01 \\
$\mathrm{~W}$ & 1.17741 & 1.794123 & 2.145966 & 2.537272 & 2.79715 & 3.034854 \\
$\mathrm{~K}_{\text {TN }}$ values & $-1 \mathrm{E}-07$ & 0.841457 & 1.281729 & 1.751077 & 2.054189 & 2.326785 \\
\hline
\end{tabular}




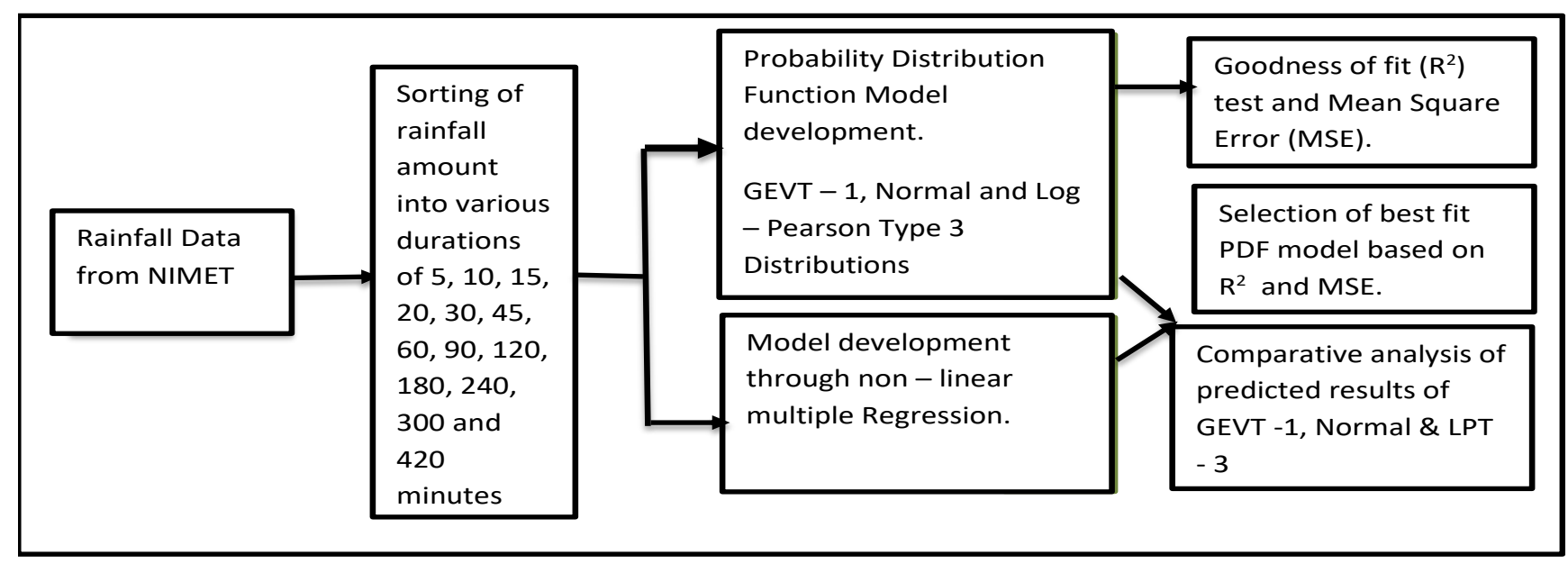

Figure 2: Graphical representation of model development, IDF

\subsection{Calibration of Sherman's IDF models: \\ 3.2.1 Specified Return periods}

The calibrated Sherman (1932) IDF models for specified return periods are as presented in Table 3. Equally included in the table is coefficient of determination $\mathrm{R}^{2}$ and mean square error (MSE) for model performance assessment. Similarly, Tables 4 and 5 showcase calibrated IDF models for Normal and Log - Pearson Type - 3 distributions alongside $\mathrm{R}^{2}$ and MSE values.

\subsubsection{Non - Specified return period (General IDF models)}

A general IDF model was also developed. A total of 13 durations multiplied by 6 return periods yielded 78 input data points. The entire input data were taken from Table 1. The general IDF model was developed using Excel Optimization Solver. The least squares equations were programmed accordingly and the resulting equation is:

$$
I=\frac{551.809 T_{r}{ }^{0.188}}{T_{d}^{0.596}}
$$

For Equation (8), the coefficient of determinant $\left(R^{2}\right)=0.990$ and Mean Squared Error $=95.27$ $\mathrm{mm} / \mathrm{hr}$. The plot of the predicted intensity values of Equation (8) is as shown in Figure 5.

Similarly, Equations ( 9 and 10 ) show the general IDF models for Normal and Log - Pearson distributions while Figures 6 and 7 show the result in plotted form.

Normal distribution:

$I=\frac{579.532 T_{r}^{0.130}}{T_{d}^{0.577}}$

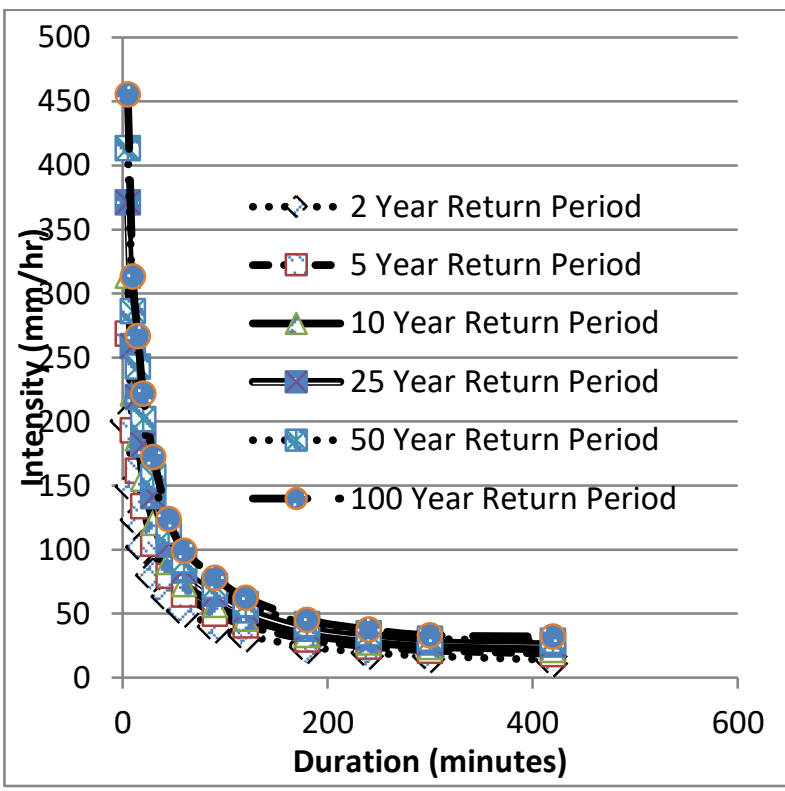

Figure 3: Intensity Duration Frequency (IDF) curves for GEVT - 1 distribution for Ikeja.

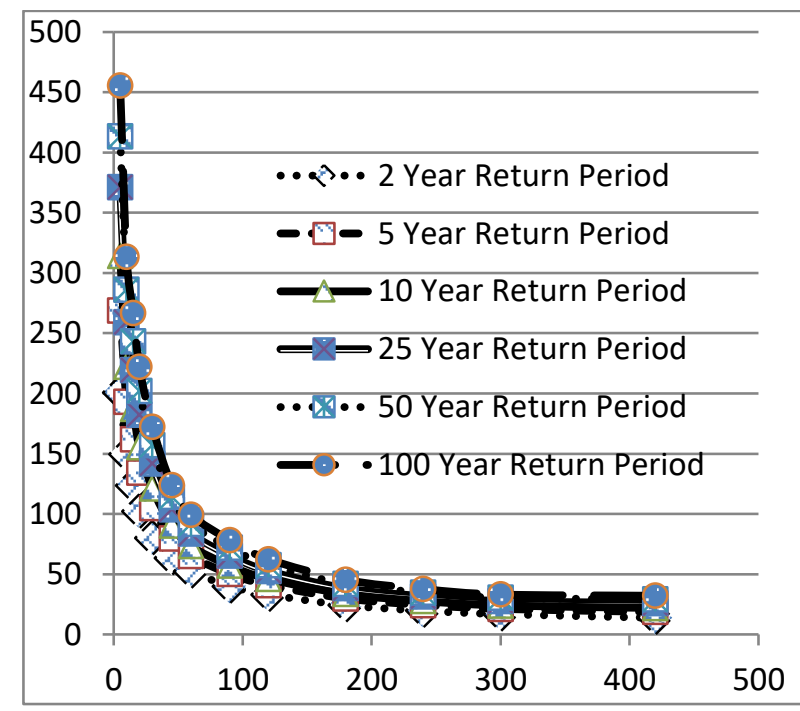

Figure 4: Intensity Duration Frequency (IDF) curves for Normal distribution for Ikeja.

Vol. 39, No. 4, October 2020 
Table 3: GEVT-1 calibrated IDF Models for different return periods for Ikeja.

\begin{tabular}{cccc}
\hline Return Period & IDF Model & Coefficient of Determination $\left(\mathrm{R}^{2}\right)$ & Mean Squared Error (MSE) \\
\hline 2 & $\mathrm{I}=\frac{4.873 T_{r}{ }^{6.700}}{T_{d}^{0.550}}$ & 0.992 & 26.43 \\
5 & $\mathrm{I}=\frac{2.240 T_{r} .564}{T_{d}^{0.550}}$ & 0.993 & 41.12 \\
10 & $\mathrm{I}=\frac{1.688 T_{r}^{2.686}}{T_{d}^{0.575}}$ & 0.993 & 54.59 \\
25 & $\mathrm{I}=\frac{1.33 T_{r}{ }^{2.055}}{T_{d}{ }^{0.583}}$ & 0.993 & 75.85 \\
50 & $\mathrm{I}=\frac{1.193 T_{r} .744}{T_{d}^{0.587}}$ & 0.993 & 94.68 \\
100 & $\mathrm{I}=\frac{1.110 T_{r} .519}{T_{d}^{0.590}}$ & 0.993 & 115.94 \\
\hline
\end{tabular}

\pm : return period specific IDF models; $T_{r}=$ return period (year) and $T_{d}=$ duration (minutes)

Table 4: Normal distribution calibrated IDF Models for different return periods for Ikeja.

\begin{tabular}{|c|c|c|c|}
\hline Return Period & IDF Model \pm & Coefficient of Determination $\left(\mathrm{R}^{2}\right)$ & Mean Squared Error (MSE) \\
\hline 2 & $\mathrm{I}=\frac{4.906 T_{r}{ }^{6.786}}{T_{d} 0.554}$ & 0.992 & 28.64 \\
\hline 5 & $\mathrm{I}=\frac{2.245 T_{r}{ }^{3.586}}{T_{d}^{0.569}}$ & 0.993 & 43.68 \\
\hline 10 & $\mathrm{I}=\frac{1.685 T_{r}^{2.684}}{T_{d}^{0.575}}$ & 0.993 & 54.01 \\
\hline 25 & $\mathrm{I}=\frac{1.307 T_{r}^{2.035}}{T_{d}^{0.580}}$ & 0.993 & 66.87 \\
\hline 50 & $\mathrm{I}=\frac{1.189 T_{r}{ }^{1.716}}{T_{d}^{0.583}}$ & 0.993 & 76.19 \\
\hline 100 & $\mathrm{I}=\frac{1.104 T_{r} r^{1.487}}{T_{d} 0.585}$ & 0.993 & 85.25 \\
\hline
\end{tabular}

Table 5: IDF Models for different return periods using Log-Pearson distribution for Ikeja

\begin{tabular}{cccc}
\hline Return Period & IDF Model \pm & Coefficient of Determination $\left(\mathrm{R}^{2}\right)$ & Mean Squared Error (MSE) \\
\hline 2 & $\mathrm{I}=\frac{4.858 T_{r}^{6.656}}{T_{d}{ }^{0.542}}$ & 0.991 & 28.24 \\
5 & $\mathrm{I}=\frac{2.233 T_{r} .3550}{T_{d}^{0.560}}$ & 0.992 & 43.36 \\
10 & $\mathrm{I}=\frac{1.689 T_{r} .685}{T_{d}^{0.573}}$ & 0.993 & 56.84 \\
25 & $\mathrm{I}=\frac{1.316 T_{r}^{2.067}}{T_{d}^{0.590}}$ & 0.993 & 82.17 \\
50 & $\mathrm{I}=\frac{1.196 T_{r} .764}{T_{d}^{0.602}}$ & 0.992 & 111.76 \\
100 & $\mathrm{I}=\frac{1.116 T_{r} .545}{T_{d}^{0.614}}$ & 0.992 & 154.85 \\
\hline
\end{tabular}
\pm return period specific IDF models

For Equation (9), the coefficient of determinant $\left(R^{2}\right)=0.990$ and Mean Squared Error $=95.29$ $\mathrm{mm} / \mathrm{hr}$.

And Log - Pearson distribution:

$$
I=\frac{519.214 T_{r}^{0.204}}{T_{d}^{0.592}}
$$

For Equation (10), $\mathrm{R}^{2}=0.990$ and Mean Squared Error $=106.86 \mathrm{~mm} / \mathrm{hr}$.

\subsubsection{Evaluation of iterative Equation Solver in Excel}

Excel Solver model parameters trial solution for return period (2 year) specific IDF model has fourteen (14) iterations before convergence (see Table 6). Similarly, there are thirty-five (35) iterations in the development of the general IDF model given in Equation (8).

The coefficient of determination is computed from Equation (11) and Table 7. 


$$
R^{2}=\frac{\sum_{i=1}^{n}\left(y-y_{\text {avg }}\right)^{2}-\sum_{i=1}^{n}\left(y-y_{\text {pred }}\right)^{2}}{\sum_{i=1}^{n}\left(y-y_{\text {avg }}\right)^{2}}
$$

The tabular evaluation of the various terms involved in the computation of coefficient of determination $\left(R^{2}\right)$ such as observed rainfall intensity (I); predicted intensity $\left(I_{p}\right)$; average intensity ( $\mathrm{I}_{\text {avg }}$; $\left(\mathrm{I}-\mathrm{I}_{\mathrm{p}}\right)^{2}$ and $(\mathrm{I}-\mathrm{Iavg})^{2}$ respectively are as presented in Table 7. Given Table 7 and Equation (11), the evaluation of $\mathrm{R}^{2}$ and Mean Square Error (MSE) are as follows:

and

$$
R^{2}=\frac{(41807.74-1098.365)}{41807.74}=0.973
$$

$$
M S E=\frac{\sum_{i=1}^{n}\left(y-y_{\text {pred }}\right)^{2}}{n}
$$

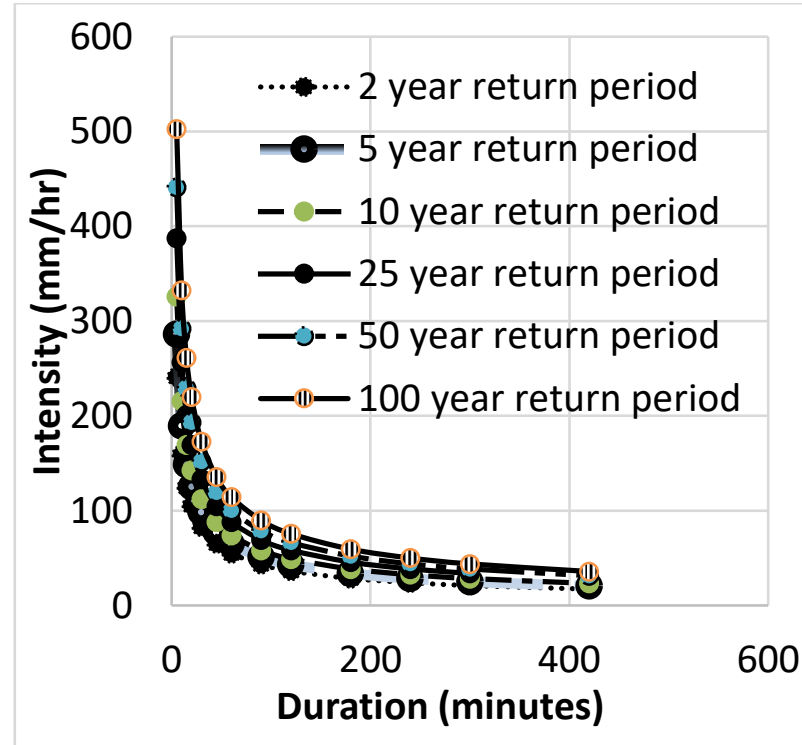

Figure 5: Intensity Duration Curve for Gumbel Extreme Value Type 1 IDF general model for Ikeja.

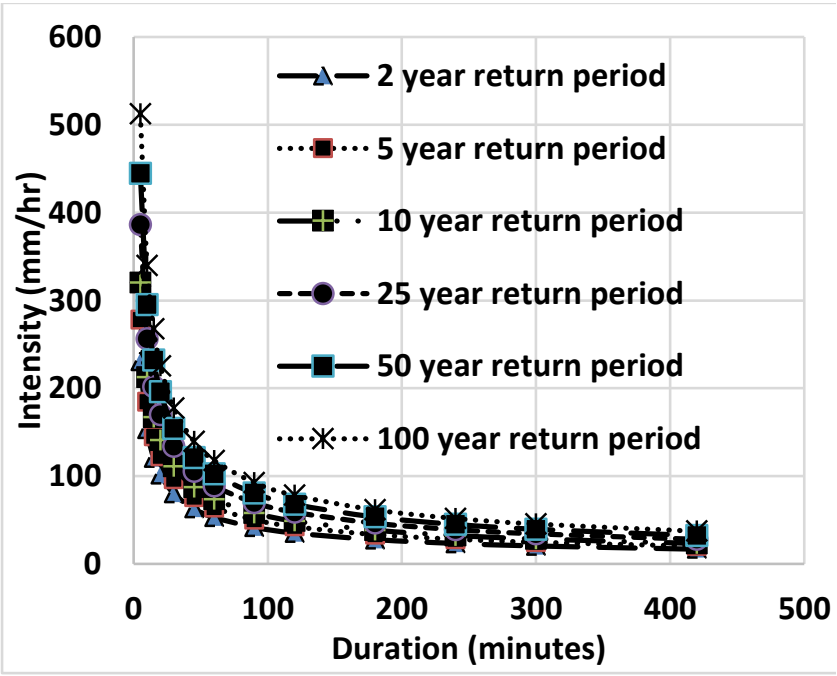

Figure 7: Intensity Duration Curve for Log Pearson Type 3 Distribution IDF general model for Ikeja.

Nigerian Journal of Technology,

$$
\text { MSE }=\frac{1098.365}{13}=84.49
$$

\subsection{Comparison of Observed and Predicted Rainfall Intensities}

The general IDF model enables one to predict the intensity of rainfall of any duration and any return period. The verification of the developed model is carried out by plotting the observed and predicted intensities on the same graph as shown in Figures 8 to 10 . Similarly, a comparartive plots for GEVT 1 , Normal and Log - Pearson Type 3 distributions for 5 and 100 year return periods are as shown in Figures 11 and 12.

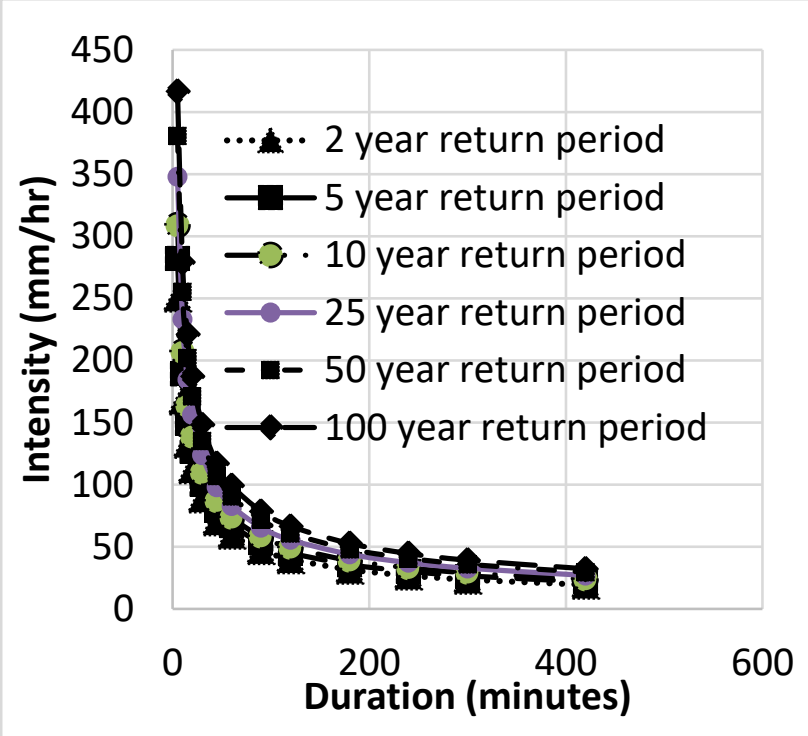

Figure 6: Intensity Duration Curve for Normal Distribution IDF general model for Ikeja.

Table 6: Trial solution result for Sherman's specific IDF model calibration for Ikeja

\begin{tabular}{cccc}
\hline Iteration & $\mathrm{c}$ & $\mathrm{m}$ & $\mathrm{a}$ \\
\hline 1 & 1 & 1 & 1 \\
2 & 1.461474 & 1.31987 & 0 \\
3 & 3.546129 & 3.431661 & 0 \\
4 & 3.825354 & 4.117993 & 0 \\
5 & 3.830287 & 4.130401 & 0.05 \\
6 & 4.528795 & 5.887498 & 0.312129 \\
7 & 4.713106 & 6.348498 & 0.400196 \\
8 & 4.838772 & 6.614912 & 0.52986 \\
9 & 4.859924 & 6.669481 & 0.538164 \\
10 & 4.857193 & 6.663613 & 0.535575 \\
11 & 4.856903 & 6.662889 & 0.535429 \\
12 & 4.856903 & 6.662889 & 0.535429 \\
13 & 4.856903 & 6.662889 & 0.535429 \\
14 & 4.856903 & 6.662889 & 0.535429 \\
\hline
\end{tabular}

Vol. 39, No. 4, October 2020 
Table 7: Evaluated terms for determining coefficient of determination for 2 year return period

\begin{tabular}{cccc}
\hline Intensity, I & Intensitypred, $\mathrm{I}_{\mathrm{p}}$ & $(\mathrm{I}-\mathrm{Ip})^{2}$ & $(\mathrm{I}-\mathrm{Iavg})^{2}$ \\
\hline 192.1498641 & 207.892929 & 247.8440829 & 14668.11 \\
155.0966423 & 143.436046 & 135.9695073 & 7065.876 \\
128.463877 & 115.444493 & 169.5043489 & 3297.745 \\
112.3163251 & 98.9639205 & 178.2867085 & 1703.91 \\
81.16415026 & 79.6511058 & 2.28930367 & 102.5414 \\
65.78223051 & 64.1071879 & 2.805767634 & 27.62183 \\
52.68677814 & 54.9554029 & 5.146658379 & 336.7629 \\
39.42640188 & 44.2308529 & 23.08274969 & 999.2854 \\
30.27733462 & 37.9165648 & 58.35783719 & 1661.422 \\
21.74873497 & 30.517145 & 76.88501435 & 2429.42 \\
18.13831768 & 26.1605922 & 64.35688805 & 2798.363 \\
15.11094943 & 23.2144685 & 65.66702178 & 3127.821 \\
11.13080687 & 19.3872836 & 68.16940809 & 3588.857 \\
\hline
\end{tabular}

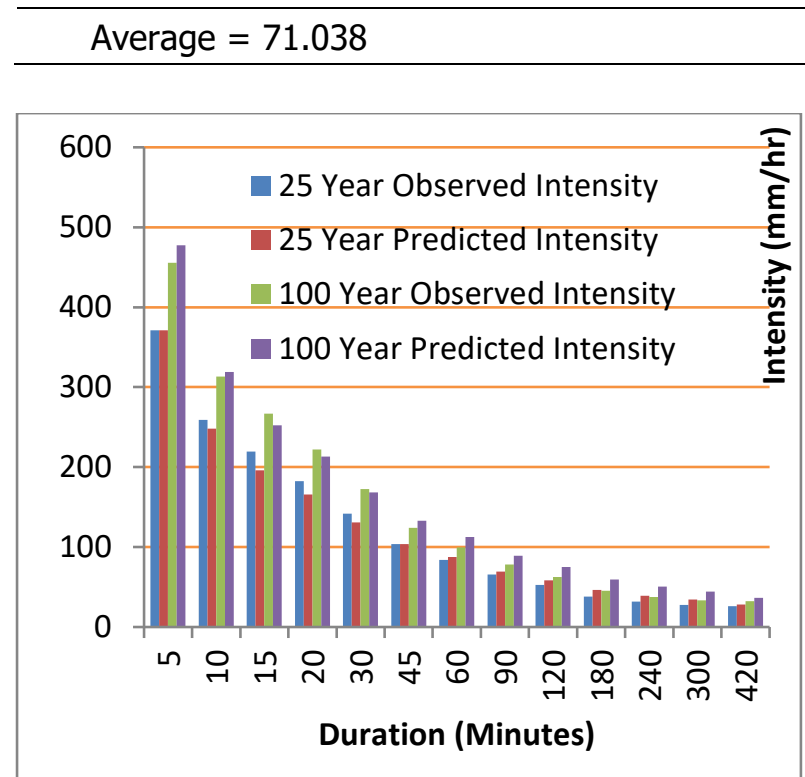

Figure 8: Observed rainfall intensity against predicted rainfall intensity for 25 and 100 year return periods for Gumbel distribution for Ikeja

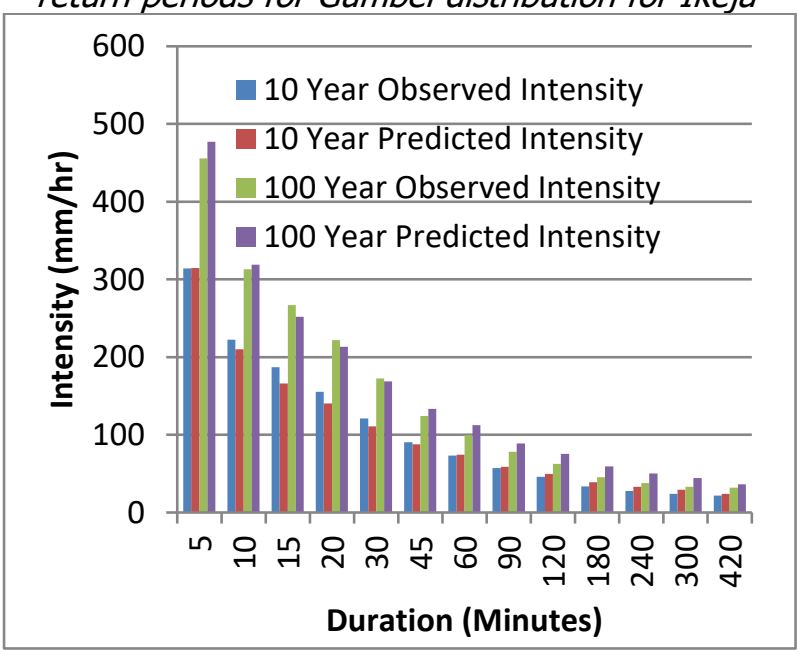

Figure 9: Observed rainfall intensity against predicted rainfall intensity for 10 and 100 year return periods for Gumbel distribution for Ikeja

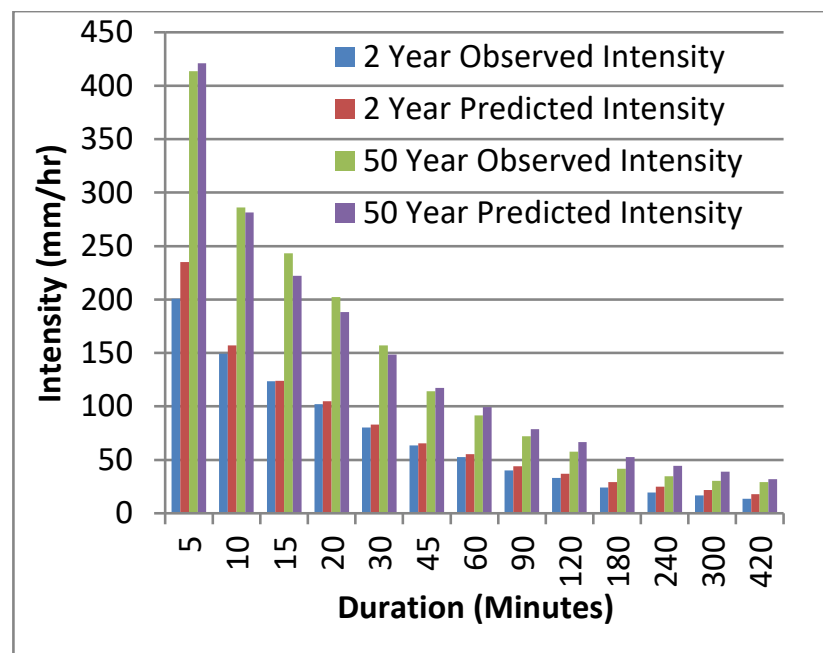

Figure 10: Observed rainfall intensity and predicted rainfall intensity for 2 and 50 year return periods for Gumbel distribution for Ikeja

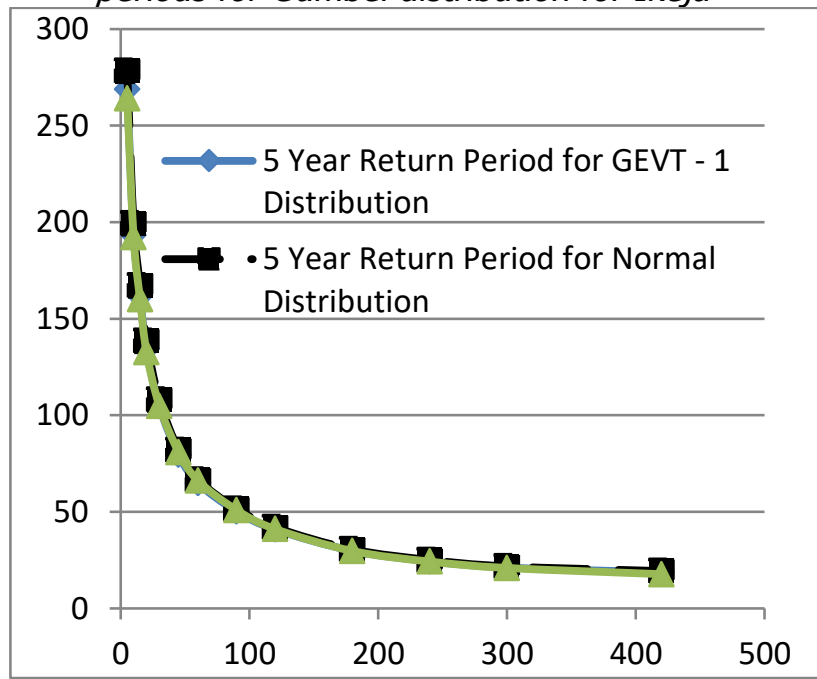

Figure 11: Plot of 5 year return period for GEVT 1, Normal and Log - Pearson type 3 distributions 


\section{DISCUSSION OF RESULTS}

Basically Table 1 is all about descriptive statistics giving information on mean and standard deviation of rainfall intensities for different durations. The result of these tables served as input data for rainfall intensity transformation using Equation 2 to obtain probability distribution function equivalent (GEVT -1 , Normal and Log - Pearson Type 3).The resulting IDF based intensity values are as plotted in Figures 3, 4, 5 and 6.

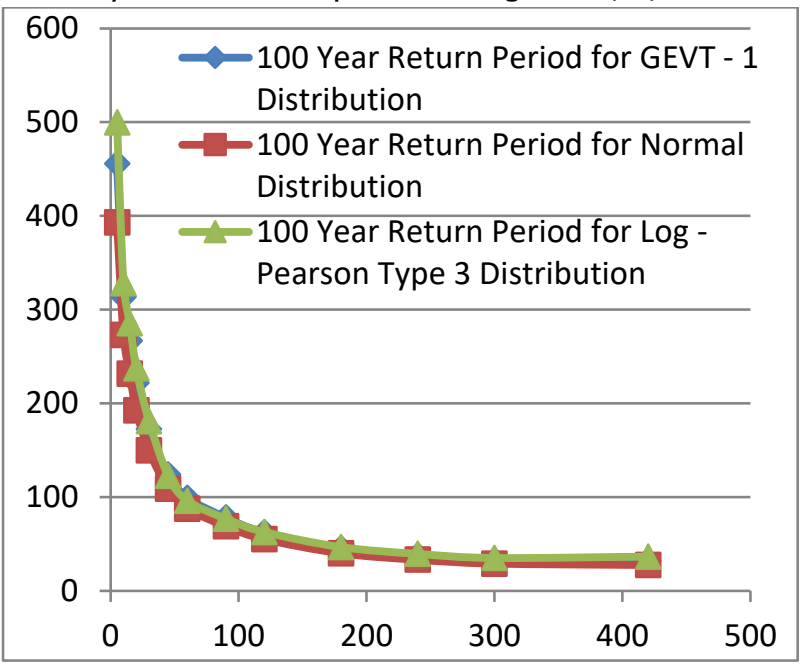

Figure 12: Plot of 100 year return period for GEVT 1, Normal and Log - Pearson type 3 distributions

Table 8: Results from regression approach and excel solver optimization approach (GEVT-1, 2 year return

\begin{tabular}{lcccll}
\multicolumn{5}{c}{ period) } \\
\hline Method & $\mathrm{c}$ & $\mathrm{m}$ & $\mathrm{a}$ & $\mathrm{R}^{2}$ & $\mathrm{MSE}$ \\
\hline Regression & 63.30 & 3.550 & 0.685 & 0.820 & 320.10 \\
Solver & 4.873 & 6.700 & 0.550 & 0.992 & 26.43 \\
\hline
\end{tabular}

\subsubsection{Performance of Regression approach against Excel Optimization Solver via $R^{2}$ and MSE}

Table 8 (an extension of Table 6 ) shows the result of the iterative method observed with Excel Optimization Solver as against regression approach. Unlike the specified return period model which is constrained by the given return period, the non - specified return period (general models) is unrestricted by the return periods. In other words, any selected return period value or duration can be used to evaluate the rainfall intensity. For GEVT - 1 and Normal distribution models selected return period of 2, 5, 10, 25, 50 and 100 years were used while various durations (minimum 5 to maximum 420 minutes), were employed to evaluate Equations 8 and 9.

The plotted graph (Figures 3 and 4) each containing a total of six plots for different return periods. Among the common features of the IDF curves observed in the plots are:

(i) Intensity decreases with increase in duration; (ii) Intensity increases with increase in return period for a given duration

Maximum intensities occur at short duration with large variations with return period, while the flattened shape observed in Figures 2, 3, 4, 5 \& 6 toward 420 minutes is because with long duration there is no much difference in intensities with return period [9].

MSE arising from evaluation of Equation (12) is reflected in Table 3 for GEVT - 1, Table 4 for Normal and Table 5 for Log - Pearson Type 3 distributions. In all the two year return periods, specific models gave the least MSE of 26.43 while the 100 year equivalent gave 115.94. However, the goodness of fit values for $2,5,10,25,50$ and 100 year return periods range from 0.992 to 0.993 . For Normal distribution in Table 4, similar observations were noted with MSE of 28.64 and 85.25 for 2 and 100 year return periods and $\mathrm{R}^{2}$ value ranging from 0.992 to 0.993 . Similar observations were made for Log - Pearson Type 3 (see Table 5), the MSE values for 2 and 100 year return periods respectively are 28.24 and $154.85=$ while the $R^{2}$ values range from 0.991 to 0.993 . Equations $(8,9$ and 10) shows that the non- specified models ranked GEVT -1 and Normal Distributions first with $R^{2}$ value of 0.990 each and MSE values of 95.27 and 95.29 while the Log-Pearson Type 3 model ranked third with $\mathrm{R}^{2}$ value of 0.990 and MSE of 106.86 .

The distribution of the observed and predicted rainfall intensities are both influenced by duration and return period. In all the plots (Figures 8 to 10), it was observed that rainfall intensity decreases with increasing duration. It was also shown in the figures that, for a given duration, the higher return period yielded corresponding higher intensity values. This observation is supported by the works of [10-17]. In Figures 11 and 12, Log - Pearson Type 3 gave the highest predicted Intensity values followed by GEVT 1 and Normal distribution. For instance at 5 minutes duration and 100 year return period, Log - Pearson Type 3 predicted $499.65 \mathrm{~mm} / \mathrm{hr}$ intensity followed by GEVT - 1 with $455.67 \mathrm{~mm} / \mathrm{hr}$ intensity while Normal distribution predicted $393.11 \mathrm{~mm} / \mathrm{hr}$ intensity. Similarly, at 60 minutes duration and 100 year return period, GEVT - 1 predicted $99.38 \mathrm{~mm} / \mathrm{hr}$ intensity followed by Log - Pearson Type 3 with $96.1 \mathrm{~mm} / \mathrm{hr}$ intensity while Normal distribution predicted 87.85 $\mathrm{mm} / \mathrm{hr}$ intensity. And finally at 300 minutes duration and 100 year return period, Log - Pearson Type 3 predicted $35.15 \mathrm{~mm} / \mathrm{hr}$ intensity followed by GEVT - 1 with $33.15 \mathrm{~mm} / \mathrm{hr}$ intensity while Normal distribution predicted $29.14 \mathrm{~mm} / \mathrm{hr}$ intensity. Apparently, the superiority of Log - Pearson Type 3 over the other two models in predicting higher intensity values at short, medium and higher durations is very consistent. 
Similar observation was noted for Port Harcourt IDF models as reported by [5].

It was observed from Table 7 that the percentage difference between observed and predicted intensity values are $7.57 \%$ for 5 minutes duration, $13.34 \%$ for 20 minutes duration and $10.85 \%$ for 90 minutes duration. As per the Excel Optimization solver, a total of 14 iterations were observed which yielded the calibrated values of $a, c$ and $m$; which are slightly different from the multiple regression approach. The bench mark for selecting the superior set of results is anchored on the goodness of fit $\left(R^{2}\right)$ and Mean Square Error (MSE) of which the values are $R^{2}=0.992$, MSE $=26.43$ for solver as against $R^{2}=0.820$, MSE $=$ 320.10 for regression approach. Thus the Excel Solver option is superior alternative to multiple regression method. These observations is in consonance with those of [4] and [5].

\section{CONCLUSION}

It has been observed for Ikeja rain gauge station that for a given return period, the intensity decreases as the duration increases which is in line with what is obtainable in literatures. Models have been developed for GEVT-1, Normal and Log Pearson Type-3 distributions which are in agreement with PDF theory which shows higher intensity occurring at shorter duration and lower intensity at longer duration. The prediction of rainfall intensity with the Probability Distribution Functions showed a good match with observed intensity values. The intensity - duration curve in all cases has a negative slope. The GEVT - 1 and Normal distribution models ranked first with respect to MSE 95.27 \& 95.29 and $R^{2}$ of 0.993 while the Log-Pearson Type 3 ranked third with MSE of 106.86 and $R^{2}$ of 0.990 in the non-specified return period (model).

\section{REFERENCES}

[1] David, A. O., Nwaogazie, I. L., \& Agunwamba, J. C. (2019a). Development of Models for Rainfall Intensity-duration-frequency for Akure, SouthWest, Nigeria. International Journal of Environment and Climate Change, 9(8): 457 466.

[2] Hosking, J. R. M., and Wallis, J. R. (1997). Regional frequency analysis: an approach based on Lmoments. Cambridge University Press, Cambridge, U.K.

[3] El-Syed, E. A. (1961), "Generation of Rainfall Intensity Duration Frequency Curves For Ungauged Sites", Nile Basin Water Science \& Engineering Journal, 4(1) pp. 112-124.
[4] Mohammad Zakwan (2016): "Application of Optimization Technique to Estimate IDF Parameters", Water and Energy International. Vol. 59, Issue 6, pp. 69-71.

[5] Nwaogazie, Ify L. and Masi, S.G. (2019): Probability and non-probability rainfall intensity duration - frequency modelling for Port Harcourt metropolis, Nigeria. International Journal of Hydrology. 3(1): $66-75$.

[6] Nwaogazie, Ify L. and Duru, E. (2002): "Developing Rainfall Intensity - Frequency Model for Port Harcourt" NSE Technical Transaction, Vol. 37, No. 2, pp. $19-32$.

[7] Www.timeanddate.com/weather/nigeria /lagos/climate.

[8] Premium Solver Platform, User Guide. 2010. Frontline Systems, Inc.

[9] Jaleel, L. A. and Farawn, M. A. (2013): "Developing Rainfall Intensity-Duration-Frequency Relationship for Basrah city. Kufa Journal of Engineering (K. J. E), Vol. 5, No. 1, pp. 105-112.

[10] Ven Te Chow, Larry, R., Maidment and Larry, W. (1988): Applied Hydrology, McGraw - Hill publishers, New York.

[11] David, A. O.; Nwaogazie, Ify L. and Agunwamba, J. C. (2019). Modeling Rainfall Intensity by Optimization Technique in Abeokuta, South West, Nigeria. Journal of Engineering Research and Reports 6(4): 1 - 10.

[12] Nwaogazie, I. L. and Nwadike, C. C. (2010): Developing Annual and Partial Series Rainfall Models for Enugu City, Global Journal of Engineering Research, 9(1 \& 2); 1 - 18.

[13] Okonkwo, G. I. and Mbajiorgu, C. C. (2010): Rainfall intensity - duration - frequency analysis for Southern Nigeria. Agric Eng. Int: The CIGR Journal; 12(1): $22-30$.

[14] Udo Inyang, C. U. and Edem, D. I. (2012): Analysis of rainfall trends in Akwa Ibom State, Nigeria. Journal of Environment and Earth Science; 2(8): 1 - 12

[15] Akpan, S. U. and Okoro, B. C. (2013): Developing rainfall intensity - duration - frequency models for Calabar city, South - South, Nigeria. American Journal of Engineering Research; 2(6): 19 - 24.

[16] Ologhadien, I and Nwaogazie, Ify L (2014): Rainfall Intensity - Duration - Frequency Models for selected Cities in Southern Nigeria. Standard Scientific Research and Essays Vol 2 (10): 509 515.

[17] Nwaogazie, I. L. and Okonkwo, S. C. (2017): Rainfall intensity-duration-frequency modelling and comparative analysis of developed models for Abakaliki, Ebonyi State, Nigeria. International Journal of Trend in Research and Development, 4(2): $776-783$. 